\title{
ОТКРЫТОСТЬ КАК ТРЕНД ЭВОЛЮЦИИ ЕВРОПЕЙСКОЙ НАУКИ
}

Аннотация. Статья посвящена анализу концептуальных перемен, происходящих в сфере исследований в Европейском союзе. Показано, что современные управленческие парадигмы в менеджменте европейской науки выглядят как единство инновачионных подходов к исследовательскому проиессу и формирования новой инфраструктуры для научного поиска. Установлено, что главным вектором движения в этом направлении выступает фено́мен открытой науки. В работе автор также рассматривает эволючию европейского научного сообщества как противоречивый процесс, который инициирует не только традиционный для науки поиск истины, но и цеели развивающегося «академического капитализма» с их предпринимательской доминантой.

Ключевые слова: открытая наука, Европейский союз, информационное общество, «академический капитализм».

Главные перемены в сфере исследований в Европе в настоящее время вызваны в первую очередь тем, что цифровому обществу оказались нужны новые управленческие парадигмы. Их ныне можно обозначить формулой: инновационные подходы и новая инфраструктура. В социокультурном контексте происходящие изменения обусловлены движением в направлении информационного/постиндустриального мира и новым концептуальным видением последнего как социума, базирующегося не только и не столько на цивилизации услуг, сколько на реиндустриализации. Последняя для своего воплощения предъявляет новые, более высокие требования к потенциальным субъектам этой деятельности. Необходимым условием для воспроизводства человеческого потенциала Старого Света как раз и выступает комплекс интеграционных стратегий Европейского союза, в том числе и в области науки.

Генезис собственно инноваций как таковых можно считать вполне традиционной стратегией для научно-технологического развития в данном регионе, имеющей целью повысить эффективность европейской экономики и обеспечить ещё более значимое, т.е. лидирующее, место европейской науки в мире. Продолжать оставаться вторым по этому показателю, причём с перспективой утратить и это место в исследовательском рейтинге и уступить его ведущим азиатским странам, Евросоюз не готов.

При этом уже очевидно, что перемены в науке региона должны инициироваться куда более сложными процессами, нежели механическое увеличение расходов на неё на уровне EC, национального финансирования, а также частных ресурсов. Так, в частности, Финляндия и Швеция уже достигали целевого показателя в 3\% от ВВП для расходов государств Европейского союза на НИОКР, однако сегодня понижают эту цифру (таблица 1). На наш взгляд, можно рассматривать эту ситуацию в качестве индикатора того, что эффективность европейских НИОКР на всех уровнях более не подчиняется сугубо линейным закономерностям.

(C) Водопьянова Елена Викторовна - доктор философских наук, профессор, главный научный сотрудник, руководитель Центра культурологии ИЕ РАН. Aдpec: 125009, Россия, Москва, ул. Моховая, д. 11, стр. 3. E-mail: veritas-41@yandex.ru.

DOI: http://dx.doi.org/10.15211/vestnikieran12019137141 
Таблица 1

Расходы на НИОКР (\% от ВВП, все сектора)

\begin{tabular}{|c|c|c|}
\hline Страна & 2008 & 2016 \\
\hline ЕС-28 & 1,84 & 2,03 \\
\hline Бельгия & 1,92 & 2,49 \\
\hline Болгария & 0,45 & 0,78 \\
\hline Чехия & 1,24 & 1,68 \\
\hline Дания & 2,77 & 2,87 \\
\hline Германия & 2,6 & 2,94 \\
\hline Эстония & 1,26 & 1,28 \\
\hline Ирландия & 1,39 & 1,18 \\
\hline Греция & 0,66 & 1,01 \\
\hline Испания & 1,32 & 1,19 \\
\hline Франция & 2,06 & 2.25 \\
\hline Хорватия & 0,88 & 0,85 \\
\hline Италия & 1,16 & 1,29 \\
\hline Кипр & 0,39 & 0,5 \\
\hline Латвия & 0,58 & 0,44 \\
\hline Литва & 0,79 & 0,85 \\
\hline Люксмбург & 1,62 & 1,24 \\
\hline Венгрия & 0,98 & 1,21 \\
\hline Мальта & 0,53 & 0,61 \\
\hline Нидерланды & 1,64 & 2,03 \\
\hline Австрия & 2,57 & 3,09 \\
\hline Польша & 0,6 & 0,97 \\
\hline Португалия & 1,45 & 1,27 \\
\hline Румыния & 0,55 & 0,48 \\
\hline Словения & 1,63 & 2,0 \\
\hline Словакия & 0,46 & 0,79 \\
\hline Финляндия & 3,55 & 2,75 \\
\hline Швеция & 3,5 & 3,25 \\
\hline Великобритания & 1,63 & 1,69 \\
\hline
\end{tabular}

Источник: http://ec.europa.eu/eurostat/data/database.

Жизнь требует принципиально иного подхода к генерации инноваций, адекватного современному глобальному и виртуально-сетевому миру. Последнее означает сетевую и самоорганизационную концепцию взаимодействия между инноваторами, менеджерами, финансистами и потребителями.

Термин «совместные системные инновации» сегодня означает ожидание формирования среды для функционирования «инновационного чуда», которая должна объединить не только формально заинтересованных управленцев и инноваторов, но ещё идеи и запросы потенциальных потребителей.

Также крайне значимым становится и изобилие форм инновационного процесса. Оно может включать в себя множество как традиционных, так и новых способов организации деятельности и способов финансирования, а также видов взаимодействия субъектов инновационного процесса. При этом речь идёт, в том числе, как о совершенствовании уже существующих технологий и научных результатов, так и о применении инноваций для некоммерческо-го использования. Подобная гибкая открытая система в состоянии успешно противостоять всем вызовам современного мира, нацеливая наиболее творческих людей на самостоятельные решения и упраздняя всяческие барьеры.

В условиях, когда инновации, а главное, создание предпосылок для них, должны интернационализироваться, безусловно, и Еврокомиссия должна будет пересмотреть некие свои базовые управленческие постулаты, прежде казавшиеся незыблемыми не только де-факто, но и де-юре. Как известно, одна из важнейших особенностей самоорганизующейся системы - это

Научно-аналитический вестник ИЕ РАН, 2019, №1 
её открытость. Пожалуй, в перспективе магистральным для Европейского союза видится создание атмосферы инновационного краудсорсинга на базе создаваемых виртуальных структур патронажа над инновациями. Собственно говоря, запуск и эффективное функционирование последних и станет реальным подтверждением действующих обратных связей между по-требителями и инноваторами.

Выход за рамки традиций, национальных барьеров и стереотипов - таков магистральный вектор становления инновационного общества будущего в Европе. Одновре́менно такое движение предполагает как использование уже известных (технопарки, бизнес-инкубаторы, платформы, сети, хабы, кластеры и т.д.), так и создание пока не апробированных институциональных форм рождения инноваций. По своей природе инновация есть преодоление стандарта и традиции. Вряд ли и сам процесс её генерации может быть инерционно-консервативным по природе.

На процессе становления новой исследовательской инфраструктуры следует остановиться подробнее. Триада движения в данном направлении - это, во-первых, открытые инновации, о которых шла речь выше, во-вторых, открытость для мира, а также открытая наука в-третьих. Нацеленность на открытость инноваций в основном совершенствует прежние инновационные стратегии Евросоюза, не изменяя их давно сложившийся вектор максимально возможного вовлечения промышленности в цикл НИОКР.

Открытость для мира, в свою очередь, означает в данном контексте содействие формированию основ для глобальной исследовательской инфраструктуры, предпосылкой для которой выступит инфраструктурное взаимодействие науки на общеевропейском уровне.

При этом открытая наука подразумевает:

- продвижение Европейского Открытого научного облака ${ }^{1}$ : запуск данного сервиса нацелен на безопасный и беспрепятственный доступ европейских исследователей к современным средствам хранения, управления и обработки данных из различных источников,

- лучшие результаты за счёт открытого доступа к публикациям и данным исследований,

- поддержку транснационального доступа к научной инфраструктуре,

- развитие электронных инфраструктур на основе ИКТ.

Предполагается, что облачная инфраструктура будет способствовать:

- исследовательской карьере,

- лучшей практике глобального поиска данных и их доступности,

- стимулированию рынка инновационных исследовательских услуг,

- уточнению моделей финансирования,

- ограничению потери данных и снижению стоимости их хранения,

- решению вопросов авторского права и обеспечению минимальной бюрократической нагрузки на учёных.

Предполагается, что первоначально данная система должна заработать на уровне науки, финансируемой государством, а потом распространиться на другие уровни исследовательского процесса. Её участники первоначально должны пройти обучение навыкам работы в данной системе.

Далее проанализируем возможные трудности на путях формирования в Евросоюзе открытого доступа к научным результатам. Ещё в 2016 г. голландское правительство выдвинуло цель, поддержанную 27 государствами - членами Евросоюза - обеспечить к 2020 г. свободный доступ к финансируемым государством научным результатам, которые должны хра-

\footnotetext{
${ }^{1}$ European Open Science Cloud (EOSC). URL: https://ec.europa.eu/research/openscience/index.cfm? pg=open-sciencecloud.
}

Научно-аналитический вестник ИЕ РАН, 2019, №1 
ниться на европейских серверах. Эта концепция основана на допущении, что издательская деятельность является неотъемлемой частью научного поиска, а «Открытый доступ - это начало мышления вокруг совместного творчества или коллективных действий, которые имеют хороший резонанс с повесткой дня ООН 2030» ${ }^{1}$.

Однако у проекта, в поддержку которого выступает как Еврокомиссия, так и учёные, есть и оппоненты, прежде всего крупные издательства, например, Elsevier, которые преследуют в первую очередь финансовые цели и не хотят терять собственную прибыль. Впрочем, сам Евросоюз, имея значительные финансовые ресурсы, может создать свою собственную научную издательскую инфраструктуру для ЕС, которая станет способствовать быстрому, недорогому научному общению, причём под контролем научного сообщества 2 .

Другим организационным препятствием на пути открытого доступа к научным результатам является то обстоятельство, что большинство исследований в Европейском союзе финансируется правительствами стран-участниц через национальные исследовательские советы и институты. Последние, чтобы вписаться в обсуждаемую организационную концепцию, должны сформировать внутри себя условие отказа от финансирования исследования, если не будет запланирована открытая публикация его результатов.

Ещё одним потенциальным препятствием для внедрения данной инициативы может стать обсуждаемая реформа авторского права с её дополнительными правовыми инструментами для ограничения доступа к интеллектуальной собственности.

В целом же систему потенциальных социокультурных ограничений на расширение открытости современной европейской науки достаточно точно описывает активно разрабатываемая в зарубежной и отечественной науковедческой литературе последнего десятилетия концепция «академического капитализма». Её последователи считают «основной тенденцией изменений современного научного сообщества распространение коммерческих практик. В этом смысле режим «академического капитализма» противопоставляется режиму «общественных благ», являвшемуся основным в 1940-80-х гг. и исходившему из того, что фундаментальная наука и высшее образование являются благами, которые не могут производиться на коммерческой основе» ${ }^{3}$. Коммерческие практики сформировали и сравнительно небольшую - в масштабах академического сообщества в целом - социальную группу учёных, максимально адаптировавшихся к ситуации и ставших «капиталистами», имеющими основания не принимать некоторые предлагаемые элементы концепции «открытой науки».

Таким образом, применительно к парадигме открытости для европейских НИОКР есть много оснований для того, чтобы присоединиться к мнению авторитетных экспертов, утверждающих, что данная концепция предлагает много хороших решений, но в настоящее время имеет недостаточно стимулов для их реализации.

\section{Список литературы}

Головко Н.В., Рузанкина Е.А. Предпринимательский университет: академический капитализм и многопользовательское управление. Власть, №5, 2016. С. 67-74.

Горохов В.Г. Как возможны наука и научное образование в эпоху «академического капитализма»? Вопросы философии, №12, 2010. С. 3-15.

\footnotetext{
${ }_{1}^{1}$ Open science in the EU. URL: http://www.universityworldnews.com/article.php?story=20180317044918836.

2 Там же.

${ }^{3}$ Коннов В.И. Столкновение интересов научных элит в условиях глобализации. Сравнительная политика, 2018, T. 9, №2. С. 6.
} 
Коннов В.И. Столкновение интересов научных элит в условиях глобализации. Сравнительная политика, Т. 9, №2, 2018. С. 5-16.

Hess D. Alternative Pathways in Science and Industry, MIT Press, Cambridge, MA, USA, 2007.

Open science in the EU. URL: http://www.universityworldnews.com/article.php?story=2018031 7044918836.

\section{References}

Golovko N.V., Ruzankina E.A. Predprinimatelskij universitet akademicheskij kapitalizm i mnogopolzovatelskoe upravlenie. Vlast’, №5, 2016. S. 67-74.

Gorohov V.G. Kak vozmozhny nauka i nauchnoe obrazovanie v ehpohu akademicheskogo kapitalizma. Voprosy filosofii, №12, 2010. S. 3-15.

Hess D. Alternative Pathways in Science and Industry, MIT Press, Cambridge, MA, USA, 2007.

Konnov V.I. Stolknovenie interesov nauchnyh ehlit v usloviyah globalizacii. Sravnitelnaya politika, T. 9, №2, 2018. S. 5-16.

Open science in the EU. URL: http://www.universityworldnews.com/article.php?story=2018031 7044918836.

\section{Openness as a Trend of the European Science Evolution}

Author. Elena Vodopianova, Doctor of Sciences (Philosophy), Professor, Senior Researcher, Institute of Europe, Russian Academy of Sciences. Address: 11-3, Mokhovaya str., Moscow, Russia, 125009. E-mail: veritas-41@yandex.ru.

Abstract. The article is dedicated to the analysis of conceptual changes in the research field in the European Union. It shows that modern executive paradigms in the management of European science look like the unity of innovative approaches to the research process and the formation of a new infrastructure for scientific research. It proves that the major vector of movement in this direction is the phenomenon of open science. In the paper the author also considers the evolution of the European scientific community as a controversial process that initiates not only the traditional scientific search for truth but also the goal of developing «academic capitalism» with its entrepreneurial dominant.

Key words: open science, European Union, information society, «academic capitalism».

DOI: http://dx.doi.org/10.15211/vestnikieran12019137141 